\title{
Bibliotecas Escolares e as Linguagens de Indexação
}

\author{
School Libraries and Indexing Languages
}

\author{
Vera Lucia Ribeiro Guim \\ Bibliotecária. Mestranda em Ciência da Informação pela UNESP - Campus de Marília \\ E-mail: verinha.guim@gmail.com
}

Profa. Dra. Mariângela Spotti Lopes Fujita

Doutora em Ciências da Comunicação pela Universidade de São Paulo - USP.

Professora titular do Departamento de Ciência da Informação da Faculdade de Filosofia e Ciências - FFC -

UNESP, campus de Marília.

E-mail: fujita@marilia.unesp.br

\section{Resumo}

A discussão sobre as linguagens de indexação se apresenta como tema deste trabalho tendo como foco as bibliotecas escolares. $\mathrm{O}$ estudo objetiva assim fundamentar a consistência das linguagens com base nos elementos presentes na indexação. Como metodologia, foram utilizadas entrevistas e observação participante tendo como objetivo verificar as linguagens de indexação nas bibliotecas escolares. Dessa forma, destacaram-se as classificações nas bibliotecas escolares da rede pública municipal de ensino. Apesar de possuírem o mesmo intuito e o mesmo publico alvo, as escolas apresentaram visões diferentes, segundo seu público usuário. Assim, destacase a influência e representação das linguagens frente às instituições bem como seu propósito e importância.

Palavras Chave: Bibliotecas Escolares. Indexação. Linguagens de indexação. Classificação.

\begin{abstract}
The discussion on indexing languages presents the theme of this work focusing on school libraries. The study aims to support so the consistency of languages on the basis of elements present in the index. As methodology, interviews and participant observation with the aim to check the indexing languages in school libraries were used. Thus, they highlighted the classifications in school libraries of the municipal public schools. Although they have the same purpose and the same target audience, the schools presented different views, according to its user audience. Thus, there is the influence and representation of the front languages to institutions as well as its purpose and importance.
\end{abstract}

Keywords: School Libraries. Indexing. Indexing languages. Classification. 


\section{Introdução}

Este estudo procura tecer algumas considerações sobre as linguagens de indexação a partir das considerações da ciência da informação com ênfase nas bibliotecas escolares.

Nesse sentido, ressalta-se a relevância da organização do conhecimento para a ciência da informação, uma vez que esta tem como objetivo estudar as teorias e metodologias ligadas à organização da informação a fim de possibilitar uma rápida e fácil localização da informação assim como seu compartilhamento e representação.

Assim esse estudo procura aprofundar-se em conceitos e definições da indexação e avaliação do uso de linguagens de indexação nas bibliotecas escolares. Possui o intuito de diagnosticar os elementos que constituem as linguagens de indexação e qual sua influencia na consistência das linguagens para bibliotecas escolares, almejando assim, propor uma análise e diagnóstico que auxiliem na resolução das problemáticas que envolvem essa área.

Parte-se da premissa que o tratamento documental, a indexação e consequentemente sua política, são determinantes para a eficácia das linguagens de indexação, independente da especialização e tipo de biblioteca, uma vez que proporcionadas as condições necessárias às atividades envolvidas e desenvolvidas pelos indexadores tornam os catálogos, manuais e/ou vocabulários cada vez mais relevantes para os usuários e profissionais. No entanto a complexidade que envolve as bibliotecas escolares tem gerado dúvidas recorrentes que, por sua vez, afetam os interesses dos bibliotecários e indexadores que buscam efetivar as linguagens de indexação de forma sistematizada e eficiente para todo um público alvo.

Nesse contexto, destaca-se a importância de fornecer subsídios metodológicos para a avaliação das linguagens de indexação, com fins específicos, buscando dinamizar o conhecimento e a organização dos sistemas de informação, considerando basicamente duas etapas: análise do conteúdo dos textos e a representação dos documentos. Ao revelar que é necessária essa integração, não significa restringir-se a trabalhar somente com uma dessas etapas, é necessária a aplicação de métodos e técnicas que proporcionem a utilização das duas etapas, a fim de que essas reflitam a prática e os princípios teóricos voltados para uma adequação das bibliotecas a partir de um conjunto de procedimentos previamente estabelecidos e muito bem fundamentados, considerando, sobretudo, o desenvolvimento de uma política de indexação clara e objetiva em relação à composição do acervo, público alvo, consistência, sistema de busca e recuperação por assunto, entre outros. 
Diante disso, a fim de contextualizar as linguagens de indexação escolhidas pelas bibliotecas escolares, optou-se por discutir as bibliotecas escolares tendo como objeto de estudo as linguagens por elas escolhidas e adaptadas.

Portanto, este estudo possibilita uma nova ocasião para demonstrar mais uma abordagem de análise das linguagens de indexação estudada na literatura; permitindo assim novas contribuições para os estudos que envolvem tanto as temáticas trabalhadas sobre as bibliotecas escolares como na indexação tendo como fundamento a ciência da informação.

A seguir serão apresentados um panorama relevante trazendo como foco a biblioteca escolar e posteriormente algumas das linguagens de indexação mais utilizadas e facilmente encontradas.

\section{Biblioteca Escolar}

A relevância das bibliotecas há muito é discutida em vários âmbitos da sociedade, principalmente por se enquadrar a diferentes especialidades. Schopenhauer (2011, p.30) no século XVIII já afirmava que “as bibliotecas são a única memória permanente e segura da espécie humana". Pierre Lévy (1998, p. 97) ao final do século XX apontou que uma "rede de bibliotecas registra a criação e a experiência de uma multidão de seres humanos, mortos e vivos. A leitura e a interpretação, de geração em geração, restabelecem o frágil fio da memória, realizam pensamentos adormecidos".

Os autores acima citados reafirmam a importância das bibliotecas enquanto memória, no entanto além da importância memorial, de guarda e preservação, as bibliotecas atuais continuamente estão modificando seu foco, que agora inclui o usuário e reafirma seus espaços como locais dinâmicos e interativos, nesses aspectos também se encaixa a biblioteca escolar que agora inclui a sala de aula e demais setores da comunidade.

Na década de 1940, Lourenço Filho já enxergava que o ensino e biblioteca são instrumentos complementares (...); ensino e biblioteca não se excluem, completam-se. Uma escola sem biblioteca é um instrumento imperfeito. A biblioteca sem ensino, ou seja, sem a tentativa de estimular, coordenar e organizar a leitura, será, por seu lado, instrumento vago e incerto.

Moro e Estabel (2008, p. 62) destacam que, 
Bibliotecas Escolares e as Linguagens de Indexação

$\mathrm{Na}$ universidade chegam poucos, mas na escola circulam milhares, por isso a biblioteca escolar congrega um universo de usuários. Neste espaço universal e democrático, por onde circulam o aluno, o professor, o diretor, o funcionário, entre outros, o acesso à informação é a chave da inclusão de todos. A biblioteca escolar perpassa a linha do tempo, seja na memória de quem por ela passou, seja no presente de quem dela faz uso, seja no futuro para a geração que virá ou que ainda não chegou à escola.

Nesse sentido a fim de atender os objetivos da comunidade escolar oferecendo seus préstimos, o conceito de biblioteca escolar deve partir de um princípio abrangente de prazer, alegria, satisfação e aprendizagem e criar boas lembranças que acompanhem a vida dos alunos. É neste espaço, único dentro da instituição, que o aprendiz encontra uma liberdade intelectual e a oportunidade de saciar sua curiosidade pessoal, construindo realmente seu próprio conhecimento. Ali, ele pode acessar e usar, criar e comunicar. (BERG, 2011, p. 96).

Os bibliotecários que atuam em escolas, quando o quadro de recursos humanos dispõe de um profissional com formação em biblioteconomia, devem acompanhar o fornecimento de informações aos usuários independente dos métodos a serem utilizados. Dessa forma, o bibliotecário procura criar e transmitir novas informações buscando proporcionar melhorias constantes na formação escolar e consequentemente no espaço da biblioteca.

\footnotetext{
A biblioteca não é mais, por consequência, um mero depósito de livros: esse o mais importante de todos os pontos característicos na evolução de seu conceito. A sua passividade substituiu-se um salutar dinamismo, a iniciativa de uma obra que é, ao mesmo tempo, de socialização, especialização, democratização e laicização da cultura. Ela desempenha, dessa forma por menos que pareça, o papel essencial na vida das comunidades modernas; é em torno dela que circulam todas as outras correntes da existência social (MARTINS, 2002, p. 325).
}

A biblioteca atual procura atender um usuário que além de compartilhar e buscar informação e conhecimento nas mais diversas fontes e suportes é um usuário ativo que procura um espaço democrático, acessível, assim faz-se necessário que o bibliotecário seja um mediador entre a informação e o usuário. O olhar em relação à biblioteca varia muito, para uns trata-se de um lugar extremamente prazeroso enquanto que para outros seria um lugar que amedronta e afasta. É fato comum que a biblioteca acarreta lembranças e experiências durante a vida escolar, assim a relação do usuário com os mais diversos tipos de biblioteca é decorrente do relacionamento do aluno com a biblioteca na escola e que caminha com o cidadão desde sua infância até sua velhice.

Atualmente o conceito de biblioteca escolar mudou, antes, vista como local de silencio, quase um templo sagrado, hoje a biblioteca pulsa vida, descoberta, alegria, prazer. Imaginar 
Vera Lucia Ribeiro Guim e Mariângela Spotti Lopes Fujita

uma biblioteca sem o burburinho de seus leitores, repletos de sonhos, expectativas, desejos é pensar em biblioteca como depósito, mausoléu. (MORO; ESTABEL, 2003 p.30)

Sendo assim as bibliotecas escolares cada vez mais buscam corresponder aos desafios de um mundo cada vez mais dinâmico, investindo em métodos e técnicas que propiciam um melhor aproveitamento da informação existente no seu ambiente. Segundo Macedo (2005, p. 149) o manifesto UNESCO/IFLA para bibliotecas escolares afirma que "a biblioteca escolar propicia informação e ideias fundamentais para o sucesso de seu funcionamento na atual sociedade - baseada na informação e no conhecimento. A biblioteca escolar habilita os estudantes para a aprendizagem ao longo da vida e desenvolve sua imaginação, preparando-os para viver como cidadãos responsáveis". Para corresponder a esse desafio os gestores das bibliotecas buscam encontrar soluções que lhes permitam explorar e usar adequadamente a informação e os dados gerados no ambiente escolar.

Segundo este mesmo manifesto da UNESCO, a missão da biblioteca escolar é a promoção de serviços de apoio à aprendizagem e livros aos membros da comunidade escolar, oferecendo-lhes a possibilidade de se tornarem pensadores críticos e efetivos usuários da informação, em todos os formatos e meios.

Assim, considerando todo o processo de ensino-aprendizagem regido por novos conhecimentos e exercício da cidadania, está inserida a biblioteca escolar, espaço este que desempenha duas principais funções, a cultural e a educativa.

Na função educativa o principal alvo a ser beneficiado são os alunos e os professores. O alunado, com benefícios para o desenvolvimento de aptidões e habilidades para a busca de informações, incentivar o prazer da leitura aos alunos e consequentemente o uso ativo da biblioteca. Quanto ao segundo, propicia os recursos e serviços necessários ao exercício de suas atividades, satisfazendo a todos os envolvidos, de acordo com o planejamento de ensino. Já na função cultural, a biblioteca escolar proporciona a comunidade usuária, todo tipo de leitura e acesso a documentos acerca da história e realidade, contribuindo para o crescimento individual e o alargamento de ideias perante mundo. Além de dar todo o suporte a instituição em manifestações culturais. (FRAGOSO, 1999).

Independente da função educativa ou cultural é vital que a biblioteca ofereça a comunidade assistência e subsídios para que os alunos aprendam de forma permanente. "A amplitude dessas funções mostra que a biblioteca escolar é um elemento estratégico dentro do 
Bibliotecas Escolares e as Linguagens de Indexação

processo ensino-aprendizagem, pois oferece recursos necessários ao seu desenvolvimento". (SEVERINO, 1998, p.4)

Cada vez mais a biblioteca se destaca como centro de aprendizagem que procura capacitar os usuários na construção de seu conhecimento objetivando assim um melhor ensino, pois a aprendizagem não se restringe apenas a sala de aula, a biblioteca complementa uma educação de qualidade. Vale ressaltar que os usuários que hoje frequentam a biblioteca escolar, amanhã serão os frequentadores de bibliotecas públicas e universitárias.

Uma das mais recentes alterações em que a comunidade escolar se insere e consequentemente a relação do aluno-leitor com a informação é o estabelecimento da lei $\mathrm{n}^{\circ}$ 12.444 de 24 de maio de 2010 que dispõe sobre a universalização das bibliotecas nas instituições de ensino do Brasil, em que constam os artigos citados a seguir. Sendo eles:

\begin{abstract}
Art. $1^{\circ}$ As instituições de ensino públicas e privadas de todos os sistemas de ensino do País contarão com bibliotecas, nos termos desta Lei. Art. $2^{\circ}$ Para os fins desta Lei considera-se biblioteca escolar a coleção de livros, materiais videográficos e documentos registrados em qualquer suporte destinado a consulta, pesquisa, estudo ou leitura. Paragrafo único. Será obrigatório um acervo de livros na biblioteca de, no mínimo, um titulo para cada aluno matriculado, cabendo ao respectivo sistema de ensino determinar a ampliação deste acervo conforme sua realidade, bem como divulgar orientações de guarda, preservação, organização e funcionamento das bibliotecas escolares. Art. $3^{\circ}$ Os sistemas de ensino do País deverão desenvolver esforços progressivos para que a universalização das bibliotecas escolares, nos termos previstos nesta Lei, seja efetivada num prazo máximo de dez anos, respeitada à profissão de Bibliotecário, disciplinada pelas Leis 4.084, de 30 de junho de 1962, e 9.674, de 25 de junho de 1998. Art. $4^{\circ}$ Esta Lei entra em vigor na data de sua publicação (BRASIL, 2010).
\end{abstract}

Uma biblioteca devidamente equipada e com recursos humanos adequados, perfeitamente consolidaria os objetivos da escola propiciando um incentivo à leitura que vá além de um hábito, mas sim um prazer, independente do suporte do material, o necessário é que o estudante compreenda o quanto a leitura é valiosa para seu próprio crescimento cultural e intelectual, além de enriquecer o vocabulário e a forma de expressar-se. Assim por meios atrativos de ensino-aprendizagem que devem ser despertados no aluno a partir da sala de aula, cabe abiblioteca proporcionar um espaço que estimule as descobertas, criatividade e constante busca de informações.

Enfatiza-se que a biblioteca escolar é um serviço de informação que busca estabelecer relações de interação entre o sujeito e a informação e a cultura, para que o mesmo seja não só receptor, mas também um produtor. Nessa concepção, a biblioteca deixa de ser apenas um espaço de difusão ou disseminação da informação e da cultura, para ser também um espaço de 
Vera Lucia Ribeiro Guim e Mariângela Spotti Lopes Fujita

expressão. (AMARO, 1998, p.58). Em outras palavras, a biblioteca escolar trata-se de um projeto institucional, em contínuo desenvolvimento.

O Brasil possui, de acordo com o censo escolar realizado em 2014 pelo INEP (Instituto Nacional de Estudos e Pesquisas Educacionais) ${ }^{1}$ aproximadamente 53 milhões de alunos matriculados na educação básica, destes $85 \%$ estudam na rede publica. No entanto os investimentos para a educação não acompanharam esse crescimento uma vez que em aproximadamente $72,5 \%$ das escolas não há biblioteca.

Evidencia-se que enquanto parte integral do processo educativo e também devido à lei 12.244/2010 o Brasil precisa construir cerca de 130.000 bibliotecas até 2020, uma vez que essa lei estabelece a existência de pelo menos um livro por aluno em cada instituição de ensino do país, tanto nas redes públicas como privadas. Sendo assim para tornar a gestão dos acervos escolares uma realidade nas escolas é necessário prover ambientes e profissionais adequados a fim de obter um retorno no âmbito escolar, assim, é necessário que a organização aja como gestora do conhecimento existente buscando beneficiar seu campo de atuação, seja ele interno ou externo.

Sendo ainda mais especifico Amato e García (1989, p.12) detalham os objetivos das bibliotecas escolares como:

\begin{abstract}
Ampliar conhecimento visto ser uma fonte cultural; - Colocar à disposição dos alunos um ambiente que favoreça a formação e desenvolvimento de hábitos de leitura e pesquisa; - Oferecer aos professores o material necessário à implementação de seus trabalhos e ao enriquecimento de seus currículos escolares; - Colaborar no processo educativo, oferecendo modalidades de recursos, quanto à complementação do ensinoaprendizado, dentro dos princípios exigidos pela moderna pedagogia; - Proporcionar aos professores e alunos condições de constante atualização e de conhecimentos, em todas as áreas do saber; - Conscientizar os alunos de que a biblioteca é uma fonte segura e atualizada de informações; - Estimular nos alunos o hábito de frequência a outras bibliotecas em busca de informação e/ ou lazer; - Integrar-se com outras bibliotecas, proporcionando: intercâmbios culturais, recreativos e de informações.
\end{abstract}

Dentre muitas funções a biblioteca escolar se encarrega de desenvolver nos estudantes o gosto pela leitura, assim como a interação e aprendizagem do uso dos catálogos e recursos informativos da biblioteca, cujo insumo principal é a informação existente. Segundo Nunes (1998, p.171)

\footnotetext{
${ }^{1}$ O Censo Escolar é um levantamento de dados estatístico-educacionais de âmbito nacional realizado todos os anos e coordenado pelo Inep. Ele é feito com a colaboração das secretarias estaduais e municipais de Educação e com a participação de todas as escolas públicas e privadas do país. Mais informações em $:\langle\underline{\text { http://portal.inep.gov.br/basica-censo }>}$
} 
Bibliotecas Escolares e as Linguagens de Indexação

\begin{abstract}
A biblioteca escolar é o centro dinâmico de informação da escola, que permeia o seu contexto e o processo ensino-aprendizagem, interagindo com a sala de aula. A partir do perfil de interesses dos usuários, dispõe de recursos informacionais adequados (bibliotecários e multimeios) provindos de vigorosos critérios de seleção, dando acesso ao pluralismo de ideias e saberes. Contribuindo para a formação integral do individuo, capacitando-o a viver em um mundo em constante evolução.
\end{abstract}

Tais apontamentos reafirmam que o tratamento da informação nas bibliotecas escolares trata-se de uma necessidade de explorar e usar o conhecimento gerado pela instituição e seus usuários, sendo que uma vez colocada em prática, às técnicas de construção das linguagens e outros, se alimentam por meio dos processos inerentes a ela, tais como: catalogação de assuntos, indexação, etc.

Entende-se também que os profissionais são responsáveis pelo êxito ou fracasso de qualquer atividade nas instituições, uma vez que de nada adianta a escola dispor de uma biblioteca bem servida de materiais e mal servidas de profissionais não garantem resultados e, porquanto, exige uma maior atenção. Enfatizando essa importância, Modesto (2005, p.192) afirma que "[...] a missão e o objetivo principal de uma biblioteca escolar moderna devem residir no oferecimento, ao estudante, de determinados espaços educativos para desenvolver a criatividade e a motivação a buscada informação, em todos os momentos de sua vida".

Junto a esta última afirmação, Macedo (2005, p.175) completa que “[...] ao entrar pela primeira vez numa biblioteca, o aluno precisa aprender a 'ler as estantes' e reconhecer os vários tipos de fontes de informação. Sem esse aprendizado, jamais o educando será um usuário independente". Essa é uma das principais razões para que as bibliotecas tenham profissionais capacitados, uma vez que ela é fator fundamental para que as ações sejam bem sucedidas na comunidade escolar.

Além dos profissionais serem essenciais para a organização da informação argumentase que a tecnologia tornou-se um importante recurso de suporte à para o acesso, tratamento e disseminação da informação. Oliveira (1972) e Milanesi (1986) comentam que a biblioteca escolar necessita de atualizações, assim como também abandonar hábitos antigos, visto que sua função é capacitar o educando a acessar conhecimentos apontados em diferentes fontes de informação contribuindo para o êxito da biblioteca. Sua importância está diretamente relacionada à rapidez e agilidade de aprendizado aos educandos, influenciando na geração de conhecimento e tomada de decisão.

Infere-se que o tratamento tanto temático quanto descritivo da informação nos ambientes escolares não se limita a um único enfoque muito menos está condicionado a lidar 
com linguagens que não sejam eficazes, porquanto o seu sucesso está relacionado à sua capacidade de uniformizar os procedimentos para que uma única linguagem, que siga os elementos da política de indexação seja suficiente para atender as necessidades de informação e conhecimento tanto do profissional quanto do educando nas organizações escolares.

\section{Linguagens de Indexação}

Para uso ideal das linguagens de indexação torna-se necessário interligar a linguagem natural utilizada pelo usuário com a linguagem designada pelo sistema de recuperação utilizado, uma vez que em determinas regiões do país uma palavra buscada pode ter outro significado. A fim de facilitar o processo de comunicação entre o usuário e o sistema são elaborados instrumentos de controle de vocabulário para uso dos termos, portanto, é necessário que exista domínio da linguagem utilizada de maneira que os termos possam ser conhecidos e facilmente utilizados pelo indexador no sistema e consequentemente pelo usuário.

De acordo com Vale (1987), a escolha de uma linguagem de indexação é um fator de grande importância para eficácia de um sistema de recuperação da informação, logo tal escolha necessita considerar os objetivos do sistema, o tipo de usuário e a abrangência ou a especificidade do assunto a ser tratado.

Em consonância com a ciência da informação compreende-se que as linguagens de indexação são ferramentas essenciais na organização da informação. A linguagem de indexação é instrumento de representação no tratamento temático documental das bibliotecas cuja finalidade é atender as metas e objetivos de recuperação da informação.

As linguagens de indexação são linguagens construídas artificialmente que visam de maneira sucinta representar o conteúdo do documento.

As linguagens de indexação são instrumentos auxiliares na atividade de representação e recuperação de informações. Atuam nos sistemas de informação orientando o indexador sobre quais os melhores termos para representação do assunto de um documento e orientando os pesquisadores na elaboração das estratégias de busca de informações no sistema. (MOURA; SILVA; AMORIM, 2002, p.4)

A norma NP 4036 define linguagem de indexação como o conjunto controlado de termos escolhidos numa linguagem natural e utilizados para representar de forma coordenada o conteúdo dos documentos. 
Bibliotecas Escolares e as Linguagens de Indexação

Assim o tratamento documental faz uso de instrumentos em que os processos de analise e recuperação da informação são de clara relevância. Entre esses instrumentos destacam-se,

[...] as linguagens documentais definidas como conjuntos controlados de termos que fornecem regras sintáticas e semânticas que tem por objeto a representação dos conceitos significativos dos temas dos documentos tanto durante a fase da indexação como durante a fase da busca da informação por parte dos usuários.

(AGUSTÍN LACRUZ; FUJITA; TERRA, 2013 p. 8 tradução livre).

As bibliotecas ou unidades de informação fazem uso das linguagens de indexação a fim de descrever o conteúdo dos documentos do acervo com o objetivo de armazená-los e recuperar as informações contidas nos documentos.

As linguagens de indexação são divididas em duas classes, as linguagens de indexação hierárquicas e as linguagens de indexação alfabéticas.

Autores como Vale (1987), Moura, Silva e Amorim (2002) e Malo (2009) destacam as linguagens de indexação hierárquicas como linguagens notacionais, como por exemplo os sistemas classificatórios da Classificação Decimal Universal (CDU) e Classificação Decimal de Dewey (CDD).

Ao organizarem as informações seguindo uma estrutura hierárquica e sistemática, as classificações consideradas linguagens hierárquicas pré - coordenadas, pois os conceitos são representados pelo indexador no momento da representação, "são instrumentos por excelência usados na organização do conhecimento, primeiro numa arrumação física, depois, e em paralelo, na organização lógica e sistemática do conhecimento em catálogos” (SIMÕES, 2008, p.36).

Sendo assim, Foskett (1969, p.55) destaca que:

A função básica de uma classificação bibliotecária na recuperação de informações é
apresentar ao leitor um mapa ou esquema detalhado do assunto que lhe interessa. Visto
que o consulente procura encontrar as informações que ainda desconhece, as
possibilidades são de que não será capaz de formular os seus requerimentos com
exatidão. Uma sequencia de documentos realmente úteis (...) levá-lo-á do território
que reconhece para o que ainda lhe é desconhecido.

A estrutura oferecida pelas classificações permite que as informações sejam agrupadas de forma coerente, contextualizada e lógica.

Os sistemas de classificações considerados mais recentes e que se popularizaram, tiveram sua origem no século XIX, a Classificação Decimal de Dewey (CDD) e a Classificação Decimal Universal (CDU). Esses esquemas de classificação bibliográfica buscam mapear o 
conhecimento em suas diferentes áreas dispondo os assuntos com base nas divisões hierárquicas partindo do geral para o mais específico.

As linguagens de indexação alfabéticas são pós-coordenadas ou pré- coordenadas. Nas linguagens pós-coordenadas os termos se coordenam durante a estratégia de busca, ou seja, após sua determinação. Nas linguagens pré - coordenadas os termos são coordenados no momento da indexação. Autores como Araújo et. al. (2011) acreditam que as linguagens de indexação pré - coordenadas funcionam melhor nos sistemas tradicionais de bibliotecas enquanto que as linguagens pós - coordenadas se destacariam em sistemas automatizados, como exemplo apresentamos os tesauros como linguagens pós-coordenadas e as listas de cabeçalhos de assunto pré - coordenadas.

As Linguagens pós-coordenadas segundo Lancaster (2002, p. 22) buscam,

1- Facilitar a representação consistente das matérias por parte dos indexadores e utilizadores que recuperam, evitando a dispersão dos elementos relacionados.

2- Facilitar a realização de uma pesquisa ampla sobre um assunto enlaçando os termos com relações paradigmáticas ou sintagmáticas.

Os tesauros continuam a ser as linguagens controladas pós-coordenadas mais utilizadas na representação e recuperação da informação.

Para a UNESCO (1973, p.6) o tesauro,

É um vocabulário controlado e dinâmico de termos relacionados semântica e genericamente cobrindo um domínio específico do conhecimento [...] É um dispositivo de controle terminológico usado na tradução da linguagem natural dos documentos, dos indexadores ou dos usuários numa linguagem do sistema (linguagem de documentação, linguagem de informação) mais restrita.

Os tesauros tiveram origem no século XX e apresenta essa dinamicidade característica de uma linguagem controlada próxima da linguagem natural, seu propósito era satisfazer as necessidades de informação de modo a possibilitar um tratamento dos conteúdos temáticos de forma mais específica, sem que houvesse qualquer perda de relações semânticas. Segundo seus principais utilizadores os tesauros adequam-se a áreas especializadas, em geral são mais fáceis de utilizar, exigem menos tempo ao indexador e eram mais rápidos na recuperação da informação. Portanto seguem os princípios da pós-coordenação.

Os Principles Underlying Subject Heading Languages publicado pela IFLA em 1999 compreende o cabeçalho de assunto como uma: 
[...] expressão linguística (uma palavra ou grupo de palavras) que representam o assunto contido num documento e que é usada para recuperação num catálogo, bibliografia ou índice. Um cabeçalho de assunto pode consistir num único elemento, se o assunto for expresso por um único termo simples, ou em diversos elementos, se o assunto for expresso pela junção de termos combinados numa cadeia, de acordo com regras de sintaxe pré-estabelecidas. (IFLA, 1999, p.1)

Dessa forma os cabeçalhos de assuntos buscam representar os assuntos em cabeçalhos estruturados. No entanto é considerada umas das linguagens mais custosas, pois exigem do indexador muito mais tempo, porém a especificidade e precisão da informação são mais garantidas possibilitando também uma maior precisão na descrição dos assuntos complexos e permitem uma percepção mais imediata, por parte do usuário.

As linguagens de indexação se fazem necessárias, pois buscam conciliar o vocabulário a ser utilizado pelo sistema, pelo indexador e pelos usuários a fim de que diferentes termos sejam usados para assuntos idênticos e assim evitando que documentos similares acabem separados.

Dessa forma a escolha de uma linguagem resulta em um dos primeiros passos para o desenvolvimento de uma politica de indexação, que procura definir o perfil da instituição e consequentemente o funcionamento do sistema de recuperação de informação.

A fim de verificar as linguagens de indexação, apresentamos no próximo capítulo as perspectivas em relação aos assuntos, sistema de recuperação da informação, perfil da comunidade usuária assim como a representação e elaboração das linguagens de indexação em bibliotecas escolares na região de Marília/SP.

\section{Uso das linguagens de indexação nas Bibliotecas Escolares de Garça/SP}

As bibliotecas continuamente procuram se adaptar as mais diversas mudanças, uma vez que informações tornam-se obsoletas o tempo todo, umas evidentemente mais rapidamente que outras e que acaba por exigir atualizações contínuas.

As bibliotecas assumem o papel de acentuar um importante recurso educativo e pedagógico enquanto unidade informacional que procura estimular a leitura e o conhecimento tanto em alunos quanto funcionários e professores. A aquisição de materiais sempre tem em vista sugestões dos professores e alunos, no entanto se faz necessário que se leve em conta as situações governamentais que são falhas e lentas em relação à compra de materiais para as escolas públicas. Isto é passível de verificação ao analisar o livro tombo e constatar o material que de fato é adquirido ou doado. 
Há escolas em que as bibliotecas tendem ainda a serem relegadas a um segundo plano, ainda que esta tendência esteja mudando com o tempo. Existem bibliotecas que são utilizadas para os mais diversos fins, há ainda outras em que simplesmente a biblioteca não funciona. Há ainda bibliotecas em que geralmente o profissional responsável não possui formação em biblioteconomia e sim de um professor. Assim duas situações são apresentadas, ou o professor procura aprender como de fato funciona uma biblioteca ou permite que a biblioteca caminhe com suas próprias pernas, quando a opção escolhida é a segunda o problema envolve os recursos humanos, pois na maioria das vezes os funcionários não recebem uma qualificação profissional adequada e sendo assim é a intuição e a boa vontade que guiam as tarefas.

Entre essas tarefas encontra-se a indexação, quando realizada, e para que seja definitivamente executada faz-se necessário que a biblioteca tenha sua linguagem previamente definida, independente destas bibliotecas serem publicas, escolares, universitárias ou especializadas.

No âmbito escolar as bibliotecas em via de regra estão presentes dentro das instituições escolares ou secretarias de educação, como é o caso da biblioteca especializada em educação de Garça/SP que abrange um acervo voltado à área pedagógica e escolar.

As bibliotecas escolares presentes na região de Marília/SP e abordadas neste artigo estão presentes na cidade de Garça SP, e separadas segundo o cunho governamental, sendo bibliotecas escolares municipais e estaduais.

Como metodologia foi aplicado um questionário com entrevista seguida de observação participante. O questionário, dirigido aos diretores de bibliotecas, possui questões sobre a cobertura do acervo, formação inicial e continuada dos funcionários e uso de alguma linguagem.

A observação participante é uma técnica de investigação que envolve desde uma entrevista até a chegada do pesquisador em seu alvo de pesquisa reconhecendo o espaço e interagindo com os sujeitos ali envolvidos, possibilitando assim uma visão geral do campo de pesquisa.

Para a observação participante a pesquisadora visitou as bibliotecas bem como as salas de leitura e pode analisar o ambiente e suas impressões e conhecer um pouco mais dos locais por meio da entrevista com seus respectivos diretores. Esta observação permitiu conhecer os 
acervos e certificar como uma linguagem de indexação pode influenciar a gestão de uma biblioteca.

As bibliotecas escolares municipais pertencem a uma rede com 9 bibliotecas e logo, seguem a mesma linguagem de indexação em sua maioria fazem uso da tabela Cutter e tem como linguagem a CDD - Classificação decimal de Dewey. Ressalta-se que apesar da lei federal de 2010 que estipula uma biblioteca em cada escola geralmente essas instituições não dispõem de um bibliotecário que diariamente esteja com suas atenções voltadas para as necessidades do ambiente escolar. Neste caso, em particular, a rede conta com uma bibliotecária que administra e professores e/ou estagiários que aprendem as funções e as executam nas bibliotecas.

Assim observou-se que bibliotecas administradas pelo poder municipal no geral apontam atualmente que os profissionais atuantes nessas bibliotecas são professores readaptados que recebem capacitação e treinamento ou aprendem mesmo com a prática a fim de que o acervo seja organizado, controlado e disseminado a seus usuários.

As bibliotecas seguem as classes da CDD, além disso, as voltadas ao ensino fundamental seguem outra classificação além da cdd guiada segundo a idade e cor, sendo elas de 0-3 anos a cor amarela, 6-9 anos etiquetas em vermelho, 9-12 anos na cor azul, além de literatura juvenil e literatura infantil-poesia. Além de estantes voltadas ao publico infantil, dispõem também de vários outros tipos de material como revistas, periódicos especializados, fantoches, entre outros.

Em relação às bibliotecas presentes nas escolas estaduais, foram observadas duas bibliotecas, e aplicados os mesmos critérios de metodologia, entrevista e observação participante, no entanto nas escolas estaduais as bibliotecas recebem a denominação de sala de leitura, dispostas na resolução SE 70 de 21-10-2011, que discorre sobre a instalação de salas e ambientes de leitura nas escolas da rede publica estadual, e considerando a necessidade de estabelecer normas e procedimentos para a atuação de professor nas salas/ambientes de leitura das escolas estaduais.

O governo estadual não estabeleceu nenhum manual ou politica que tenha uma rede que incorpore todas as bibliotecas escolares do estado, estipulando uma linguagem de indexação para todas de forma democrática.

Dessa forma observou-se que as salas de leitura das escolas estaduais se voltam para o público do ensino fundamental e médio, devido a isso a sala de leitura apresenta outro ambiente, 
Vera Lucia Ribeiro Guim e Mariângela Spotti Lopes Fujita

não tão infantilizado, porém agradável de igual maneira tal qual às bibliotecas das escolas municipais, com várias mesas e uma iluminação adequada. Entretanto, observou-se que as salas de leitura não apresentam nenhuma linguagem de indexação, o acervo é classificado e distribuído nas estantes de acordo com seu assunto, não há um tratamento documental de classificação ou indexação. Outra diferença foram às classificações por cores, encontradas nas bibliotecas municipais e não disponíveis nas salas de leitura. Os livros são anotados por seu número de tombo e organizados segundo o assunto disposto na ficha catalográfica presente nos livros.

As salas de leitura não possuem softwares que lidem com seu acervo e empréstimos e devoluções, tudo é anotado manualmente. Quanto ao acervo em sua maioria é formado por doações que o governo estadual envia as escolas, assim como kits literários para os alunos no inicio do ano letivo.

Destaca-se assim que as salas de leitura de fato não fazem uso de uma linguagem de indexação, essa discrepância entre biblioteca e salas de leitura apresentam discussões entre visões que afirmam que as salas de leitura implantadas pelo governo do estado de São Paulo são um modo de burlar a lei 12.244/2010 que dispõe a obrigatoriedade de bibliotecas e bibliotecários em todas as instituições públicas do país. Enquanto que há quem acredite que as salas de leitura impulsionariam o crescimento de leitores nas escolas.

De acordo com a lei 4.084/62, regulamentada pelo decreto 56.725/65, a organização, direção e execução dos serviços técnicos das bibliotecas de qualquer tipo, inclusive as escolares compete ao bacharel em biblioteconomia. No entanto, face à carência de elemento humano com titulação especifica e considerando que a maioria das escolas não disporia, por ora, de recursos para a manutenção de um bibliotecário titulado, alternativas tem que ser buscadas para suprir essas instituições com elementos que possam desempenhar tão importantes tarefas.

De fato o foco deste artigo não se objetivou a diferenciar as salas de leitura e bibliotecas em si, mas sim a linguagem escolhida para cada acervo. As diferenças entre as duas quanto à linguagem do acervo são várias. Dessa forma é possível verificar o quanto um tratamento documental se faz necessário, o mesmo afirmaram os profissionais responsáveis por cada instituição. 
Bibliotecas Escolares e as Linguagens de Indexação

A linguagem escolhida pelas bibliotecas municipais se mostra mais completa, pois faz uso de linguagem de indexação, aproximando o usuário e possibilitando que o acervo esteja bem representado e de fácil recuperação.

A lei 12.244/2010 propõe que exista no mínimo um livro para cada aluno matriculado. Enfatiza-se que por serem escolas de cunho governamental diferente, as visões também divergem, sendo assim uma classificação por assunto é mais fácil de manuseio, e é a mais facilmente encontrada na rede estadual, entretanto não é precisa e tampouco contempla as minucias e particularidades de cada assunto.

Sendo assim percebe-se que as diferentes linguagens e suas metodologias e métodos traduzem-se enquanto fundamentais uma vez que permite a construção de sistemas e de pesquisas tendo em vista seus objetivos e fundamentos.

Enfatiza-se assim que tanto a experiência quanto o conhecimento do profissional ao traduzir, representar uma linguagem deve considerar todos os aspectos, objetos e interpretações que se seguem a ela, uma vez que quando representado o documento, tanto as linguagens quanto as interpretações e significados são avaliados, esta é apenas uma das discussões que envolvem o profissional bibliotecário e que não está presente na formação do professor, estes tópicos correspondem a apenas um dos muitos que atualmente se discutem, porém não serão discutidos a fundo neste estudo, mas são informados a fim de trazer uma maior clareza e interesse para a continuidade deste estudo. 


\section{Considerações finais}

Diante de diversas aplicações e adaptações os estudos envolvendo as bibliotecas escolares estão cada vez mais relacionada e interconectada com as mais distintas áreas do conhecimento. A sua relevância frente às linguagens está firmada e inferida em seus estudos.

As funções e ações das linguagens para a indexação é de clara importância e condicionalidade. Cada aplicação aponta seu fundamento e abordagem, assim como outros questionamentos, visando assim contribuir para o aprofundamento das questões de representação e tradução das linguagens de indexação, ponderando seu alcance e escopo em relação às bibliotecas escolares.

Sendo essas, tidas como fundamentais para uma descrição e indexação adequada aos sistemas e meios informacionais, pressupõe-se que as experiências a que as linguagens de indexação são acometidas possam sugerir a cultura, o meio ambiente, a educação e até mesmo o emocional que as bibliotecas escolares utilizam para os fins de pesquisa.

Em suma, todos os processos e abordagens citados no decorrer deste ensaio foram sucintos. Considera-se extremamente fundamental que uma pesquisa mais estruturada e detalhada seja necessária tanto para as abordagens em relação às bibliotecas escolares como para as linguagens de indexação. Por serem temas abrangentes e referidos entre si.

Infere-se também que a forma estruturada das linguagens, suas traduções e representações nas instituições sendo elas dos mais variados cunhos governamentais, influenciam diretamente nos propósitos da unidade informacional.

Considerando isso, os autores, citados neste estudo, reforçam a necessidade de uma linguagem de indexação estruturada a partir da profundidade teórica fornecida pelos ambientes escolares e que busca ser entendida como ferramenta imprescindível de modo a promover e agregar valores, eficácia e consistência a informação. 


\section{Referencias}

AMARO, R. K. O. F. Biblioteca interativa: concepção e construção de um serviço de informação em ambiente escolar. São Paulo: ECA-USP, 1998.

AMATO, M.; GARCIA, N. A. R. A biblioteca na escola. In: GARCIA, E. G. (Coord.). Biblioteca escolar: estrutura e funcionamento. São Paulo: Loyola, 1989. p. 9-23.

AGUSTIN LACRUZ, M. C.; FUJITA, M. S. L.; TERRA, A. L. S. Indizar, clasificar y organizar las colecciones de las bibliotecas escolares: herramientas en lengua española y portuguesa. In: RIBEIRO, F., CERVEIRA, M. E. (Org.). Informação e/ou conhecimento: As duas faces de Jano: Atas do I Congresso ISKO Espanha e Portugal e XI Congreso ISKO España. 1ed. Porto: Faculdade de Letras da Universidade do Porto; CETAC. MEDIA, 2013, v. 1, p. 701-717.

ARAÚJO, H. C. B. et. al. Linguagens de indexação: uso das linguagens presentes na prática da indexação. In: ENCONTRO REGIONAL DE ESTUDANTES DE BIBLIOTECONOMIA, DOCUMENTAÇÃO, CIÊNCIA DA INFORMAÇÃO E GESTÃO DA INFORMAÇÃO, 14., 2011. Atas. São Luis: Universidade Federal do Maranhão, 2011.

BERG, K. Competência em informação e bibliotecas escolares: entrevista. In: Revista Brasileira de Biblioteconomia e Documentação: Nova Série, São Paulo, v. 7, n. 1, p. 92-97, jan./jun. 2011.

BRASIL. Lei ${ }^{\circ} 12.444$ de 24 de maio de 2010: Dispõe sobre a universalização das bibliotecas nas instituições de ensino do País. Diário Oficial da União, Brasília, 25 maio 2010.

FOSKETT, D. J. Serviço de informação em bibliotecas. São Paulo. Polígono, 1969.

FRAGOSO, G.M. A biblioteca na escola. Revista Dois pontos: teoria e prática educacional. v. 4, n. 39, p. 39-42, nov./dez. 1999.

IFLA/UNESCO. A biblioteca escolar no ensino-aprendizagem para todos. Manifesto da Biblioteca Escolar da IFLA/UNESCO. 1999

LANCASTER, F.W. El control del vocabulario en la recuperación de información. 2. ed. Valencia, 2002.

LÉVY, P. A inteligência coletiva: por uma antropologia do ciberespaço. São Paulo: Loyola, 1998

LOURENÇO FILHO, M.B. O ensino e a biblioteca. Rio de Janeiro: Imprensa Nacional, 1946. $1^{a}$ Conferência da Série "A educação e a biblioteca", pronunciada na Biblioteca do DASP, em 05/07/1944.

MACEDO, N.D. (Org.). Biblioteca escolar brasileira em debate: da memória profissional a um fórum virtual. - São Paulo: Editora SENAC; Conselho Regional de Biblioteconomia - $8^{\mathrm{a}}$ Região - São Paulo, 2005 
MALO, M. J. O. M. C. As bibliotecas escolares e as linguagens documentarias: propostas metodológicas de uma lista controlada de termos: Lisboa, 2009 (Mestrado em gestão da informação e bibliotecas escolares).

MARTINS, M. H. Recepção e interação na leitura. In: YUNES, E. (Org.). Pensar a leitura: complexidade. Rio de Janeiro: PUC-Rio; São Paulo: Loyola, 2002.

MODESTO, F. et al. Biblioteca escolar brasileira em debate: da memória profissional a um fórum virtual. São Paulo: Senac/ Conselho Regional de Biblioteconomia - 8 a região, 2005.

MORO, E.L.S.; ESTABEL, L.B. O encantamento da Leitura e a Magia da Biblioteca Escolar. Educação em Revista, v.7, n. 40, out.2003.

MORO, E. L.S.; ESTABEL, L.B. O processo da leitura na família, na escola e na biblioteca através das tecnologias de informação e de comunicação e a inclusão social das pessoas com necessidades educacionais especiais. Porto Alegre, 2008

MOURA, M. A.; SILVA, A. P.; AMORIM, V. R. A concepção e o uso das linguagens de indexação face às contribuições da semiótica e da semiologia. Informação e Sociedade: Estudos, v. 12, n. 1, 2002.

MILANESI, L. Ordenar para desordenar: centros de cultura e bibliotecas públicas. São Paulo: Brasiliense, 1986.

NUNES, W. A. Biblioteca escolar no sistema de ensino brasileiro: um desafio em tempos de leitura e uso da informação. São Paulo: FEA-USP, 1998 (Tese de doutorado)

OLIVEIRA, A. L. Escola e biblioteca. Revista da Escola de Biblioteconomia da UFMG, Belo Horizonte, v. 1, n. 2, p. 184 - 195, set. 1972.

SCHOPENHAUER, A. A arte de escrever. Porto Alegre: L\&PM, 2011.

SEVERINO, T. M. A contribuição do bibliotecário para o processo ensinoaprendizagem: um estudo das bibliotecas particulares de ensino de $1^{\circ}$ grau de Curitiba. Curitiba, 1998.

SIMÕES, M. G. Da abstração à complexidade formal: relações conceptuais num tesauro. Coimbra: Almedina, 2008

UNESCO. Guidelines for the establishment and development of monolingual thesauri. Paris: Unesco, 1973

VALE, E. A. Linguagens de indexação. In: SMIT, J. W. (Coord.). Análise documentária: a análise da síntese. Brasília: NCT - CNPQ, 1987. Cap. 1, p.12 - 26. 